\title{
К ВОПРОСУ О ВИДАХ ДРАМАТУРГИЧЕСКОГО ПЕРЕВОДА
}

\author{
Мачей Малек
}

TO THE ISSUE OF DRAMA TRANSLATION

Maciej Malek

\begin{abstract}
Резюме: Статья посвящена драматургическому переводу и его видам. Автор проанализировал доступные реализации драматургических текстов и на их основе выделил несколько видов, с учетом техники их перевода. Автор обращает также внимание на проблемы, возникающие при переводе данного типа текстов. Все виды переводов проиллюстрированы соответствующими примерами на мировых сценах: польской, русской, чешской, канадской и др.
\end{abstract}

Ключевые слова: перевод драмы, сценический перевод, виды перевода

\begin{abstract}
The article brings arguments in favour of the ways of drama translation. Author analysed all available stage realisations of dramatic texts. On their example distinguished few ways of translation taking into account the translation techniques. Each of these ways was described and illustrated by relevant examples from world's stages: Polish, Russian, Czech, Canadian etc. Author draw also attention to challenges faced by the translators.
\end{abstract}

Key words: Drama Translation, Stage Translation, Ways of Drama Translation

DOI: $10.14712 / 9788076032088.12$

Перевод можно определять по-разному, но все дефиниции сходны в том, что это сложная задача. Дефиниция перевода, понимаемого как:

«Отыскание в другом языке таких средств выражения, которые обеспечивали бы передачу на него не только разнообразной информации, содержащейся в данном речевом произведении, но и наиболее полное соответствие нового текста первоначальному также и по форме» (Ахманова 2004, 316)

раскрывает многоаспектность этого процесса. К этому можно еще добавить дифференциацию самого вида перевода. С такой ситуацией имеем дело в случае драматургического перевода (перевода драмы).

Слово драматургия толкуется в энциклопедиях следующим образом: 1) Один из трех основных родов литературы; 2) Совокупность литературных произведений (как правило, написанных для постановки на сцене) (Энциклопедия Кругосвет, онлайн). Придерживаясь данного положения, перевод драматургии можно понимать как исходный для целой дисциплины, независимо от ее подразделений. Важно подчеркнуть современный статус перевода драмы - перевод драмы является одной из самых актуальных тем в переводоведении. Сомнению не подлежит то, что этот вид перевода по сравнению с другими видами художественным или специальным, является более сложным. Сусан Басснетт, одна из важнейших исследователей драматургического перевода, сравнивает этот процесс с выходом из лабиринта (Басснетт 1998, 92). 
В настоящей статье мы хотим показать и коротко охарактеризовать виды драматургического перевода. Потом обсудим проблемы, стоящие перед переводчиком определенных видов, а в конце представим мнение практиков театра.

\section{Перевод драмы в исследованиях}

До сих пор в мировых исследованиях переводимый текст редко обсуждался с точки зрения своей жанровой принадлежности. Чаще всего внимание исследователей и критиков перевода было сосредоточено на переводе эпоса и лирики. Перевод драмы долгое время оставался вне их внимания. Это непосредственно связано с разногласием относительно происхождения / принадлежности драмы. Можно здесь различить два главных направления. Первое считает драму третьим родом литературы наряду с эпосом и лирикой. Второе - драма принадлежит музам театра - Мельпомене и Талии. Безусловно, такое четкое разграничение не способствовало дискуссиям на тему роли драмы (Skwarczyńska 1973, 83-84; Басснетт 20026 134135). Более широкое толкование этого вопроса дает больше возможностей при анализе данного вида перевода. Современные исследователи сходятся во мнении, что нельзя точно разграничивать исследований над драмой, так как каждая из дисциплин имеет свои инструменты, нужные для анализа произведения. В то же время, центральным становится вопрос о конечном результате перевода. Чешские исследователи, Злата Куфнерова и Здена Скоумалова, предлагают два подхода к переводу драматургических текстов. Они выделяют, вопервых, литературное произведение - издание печатной версии. В последнее время - это далеко не распространенный вид перевода из-за экономических условий (Parchem 2014, 73). Вовторых, это перевод для позднейшей постановки (Kufnerová, Skoumalová 1994, 140). Теоретический анализ литературы позволяет сделать вывод о том, что конечной и целевой формой драмы является ее постановка (Skwarczyńska 1973, 84; Csató 2003, 122].

\section{Перевод драмы как литературного произведения}

Если рассматривать драму как литературное произведение, тогда в распоряжении переводчика имеются все инструменты, используемые при переводе других литературных произведений. Но одновременно ему следует преодолеть и типичные для них барьеры. Любой художественный текст обладает своеобразной идейно-художественной спецификой. Тем самым, переводчик должен обладать не только языковой, логической, энциклопедической и риторикопрагматической компетенцией, но также литературной, основанной на знаниях и чувствительности. Это помогает ему понять символику произведения (Tokarz 2010, 7-8). Опираясь на труды многих лингвистов (Levy 1974, Bassnett 2005, Carmen-Millan 2013, Hejwowski 2015, Lewicki 2017), исследовавших проблему перевода, а также собственные замечания, мы можем попытаться назвать ряд вызовов, стоящих перед переводчиком во время работы с художественным текстом. Итак, можно здесь выделить такие проблемы как: перевод лексикосемантических значений, культурных кодов, эстетических элементов, языковой игры, юмора или конкретных единиц, таких как - имена собственные, идиомы и фразеологизированные конструкции, неологизмы, гибридные формы, а также пол и грамматический род, аспекты коммуникационный, диахронический, синхронический, формальная и жанровая стороны... Это далеко не все элементы, которые можно рассматривать в качестве барьеров, усложняющих перевод. Но ввиду того, что эта проблема является предметом самостоятельного исследования, 
выходящего за рамки нашей работы, мы хотим лишь создать фон для дальнейших исследований. Поскольку драматургия является также и литературным родом, все вышеприведенные элементы присутствуют и в процессе перевода драмы как театрального искусства.

\section{Перевод драмы как театрального искусства}

Выявление особенностей драматургического перевода как театрального искусства является тем основанием, на который опираются все остальные аспекты наших исследований. Перевод драмы, рассматриваемый в категориях литературного перевода, не доставляет переводчику особых проблем. По другому обстоят дела в случае театрального перевода ${ }^{1}$. Переводчик не имеет в своем распоряжении аналогичных инструментов. Помимо прочего, в качестве переводческой доминанты могут выступить аудиальная и исполнительная стороны текста. Но прежде чем привести эти характеристики, следует объяснить, что даже здесь театральный перевод имеет свои разновидности. Он подразделяется в зависимости от способа реализации текста и применяемой переводчиком техники:

I. Перевод техникой субтитров - перевод в виде текста для реализации в качестве субтитров;

II. (Многоголосный) закадровый перевод - перевод, осуществляемый в конечном этапе диктором;

III. Перевод сценария для постановки в ЯП - перевод, реализуемый актерами на их родном языке.

Эти три техники были выявлены нами в процессе анализа сценических реализаций в Польше, России, Чехии, Австрии и других странах. Поскольку нет названий для техник сценического перевода, приведенные выше названия основаны на теории, разработанной исследователями аудиовизуального перевода.

\section{Перевод техникой субтитров}

Под этим понятием будем подразумевать перевод, который на сцене осуществляется с помощью титров (а также их всех разновидностей: субтитры, интертитры, супратитры, сюртитры, супертитры и др.). Это довольно популярная форма текстовой реализации, которая применяется, чаще всего, в опере и оперетке, а в настоящее время также и в театре. Титры используются, во-первых, для того, чтобы, продублировать сказанное (или спетое) на том же языке на сцене. Во-вторых, тогда, когда на сцене язык оригинала может быть непонятен зрителям, например, когда выступает иноязычная театральная группа с другой страны. Втретьих, когда в данной стране сильное влияние другой нации и языка - примером может здесь послужить театр Шаушпильхаус в Цюрихе, в Австрии, Шведский театр в Финляндии, а также Ванемуйн в Тарту, в Эстонии и многие другие места. В-четвертых, для людей с ограниченными возможностями слуха.

В англоязычной литературе этот способ называется: surtitles, supertitles, SurCaps, OpTrans. Слово surtitle происходит из французского, где sur означает «над» или «на», и английского, где

\footnotetext{
${ }^{1}$ который называют также: сценическим переводом, переводом для сцены, переводом для театра.
} 
слово title непосредственно относится к слову subtitle (русс. субтитры). Что интересно, само слово Surtitle является товарным знаком Канадской оперы (Smith, онлайн).

Перевод техникой субтитров сосредоточивается на передаче диалогов и высказываний, которые потом показаны на экранах, обычно над сценой. Хотя бывают и такие театры, в которых экран находится сразу перед зрителем, в спинке впереди стоящего кресла (Венская государственная опера, Австрия); театры, в которых зритель у входа в зал получает индивидуальный компьютер-планшет и может на нем выбрать один из многих доступных языков (Мастерская Петра Фоменко, Россия), или театры, в которых текст появляется сбоку главной сцены (Шаушпильхаус в Цюрихе, Швейцария).

Для осуществления такого вида работы в театре должен присутствовать титровальщик, задачей которого является высылать сигналы из пульта в соответствии с тем, что происходит на сцене. Нередко бывает и так, что эту работу выполняет сам автор перевода. Переводчик должен учитывать характеристику такой реализации. Тогда, кроме художественного содержания текста, он принимает во внимание технические ограничения, такие как: количество знаков, которые сможет прочитать в определенное время среднестатистический зритель. Иначе говоря, это компрессия текста, сведение к минимуму числа строк субтитров, выбор самых емких форм выражения, отказ от некоторых элементов, которые имплицитно понятны или могут быть заменены другим кодом (например, жестом актера). Это касается, в частности, междометий или наречий (Горшкова 2006, 141-144). Кроме того, есть еще элементы типичные для художественного перевода (мы их привели раньше), препятствующие рецепции текста. Тогда суть работы переводчика заключается в том, чтобы, несмотря на трудности, осмыслить их и передать колорит оригинала.

\section{(Многоголосный) закадровый перевод}

(Многоголосный) закадровый перевод будем понимать как вид перевода, который на конечном этапе осуществляется диктором, в качестве которого может выступить и сам переводчик. Данный тип перевода можно сравнить с устным, т.е. и в том, в другом это может быть синхронный и последовательный переводы. Есть также подобия к переводу с листа. Это связано с тем, что, как правило, диктор читает заранее подготовленный текст. Однако, он должен знать язык оригинала, чтобы аккуратно реагировать на действия, происходящие на сцене. В Театре имени Галиаскара Камала в Татарстане, например, драмы переводятся синхронно на русский и английский языки (Гайнанова, онлайн). И хотя эти переводы заранее подготовлены, переводчик должен быть внимательным, так как и здесь существует некая доля импровизации, когда актеры меняют текст сценария. Переводчик должен донести до зрителя максимально точный перевод. Для того он должен следить за ходом действий на сцене, за речью героев и скоростью высказывания. Как видно, здесь присутствуют проблемы, типичные для устного перевода распределять свое внимание между восприятием речи и устным оформлением перевода, переключаться с одного языка на другой, $и$ - прежде всего - успевать это делать так, чтобы перевод на самом деле был синхронным. Этот процесс напоминает закадровый перевод, встречаемый в кино. Это наложение новой звуковой дорожки поверх уже существующей. Мы добавили «многоголосный» потому, что один спектакль может переводить двое или больше переводчиков с подразделением на роли. Чаще всего мужские и женские. В случае такой работы, переводчик сначала работает с письменным текстом. На этом этапе он старается сохранить информативность текста и обеспечить функционально-коммуникативное и 
эстетическое воздействие перевода. Затем обеспечивает синхронное звучание текста перевода с оригинальной звуковой дорожкой (Аносова, онлайн, 181). В случае перевода для сцены, это осуществляется, как правило, во время репетиции.

Существуют также случаи, когда используется последовательный перевод. Однако нам кажется, что это часть перформанса, одной из функций которого является передача сообщения. Примером может здесь послужить пьеса и моноспектакль Евгения Гришковца - Как я съел собаку. Евгений Гришковец выступал с ней во многих городах России и Европы, например, в театре Стефана Ярача в городе Ольштын в Польше (NDiaye 2016, 164-167) или в Театре "Без забрадли» в Праге, в Чехии (Калинина, онлайн). Здесь важен сюжет - повествование ведется от первого лица самим автором, как воспоминание человека о детстве, отрочестве и морской службе. В случае постановок за рубежом, на сцене присутствует переводчик, который последовательно переводит высказывания героя. Переводчик выбран самим автором, с учетом пола, возраста, профессионального опыта. Гришковец подчеркивает, что переводчик тогда не переводит, а создает новый вариант спектакля и, как сам говорит, «В данной ситуации переводчик - почти персонаж спектакля» (Гришковец, онлайн). Здесь переводчик дополнительно сталкивается с удержанием в памяти всего сообщения.

Несмотря на вид перевода, переводчик должен сохранить здесь оригинальный замысел произведения, его стиль и характеристики устной речи.

\section{Перевод сценария для постановки в языке перевода}

Это описательное название, которое однако указывает на цель данной техники перевода. Это самый встречаемый вид сценического перевода. Его используют тогда, когда произведение иностранного автора переводят для реализации на другом языке. Он также довольно хорошо разработан исследователями. Весьма полезными для нас оказались результаты исследований следующих ученых: Jiř́ Levý, Umění překladu (1963), Sussan Bassnett, Translation Studies (1980), Ways through the Labyrinth: Strategies and Methods for Translating Theatre Texts (1985), Patrcie Pavis, Theatre at the Crossroads of Culture (1992) Mary Snell-Hornby, Translation Studies: An Integrated Approach (1995), Sirkku Aaltonen, Time-Sharing on Stage. Drama Translation in Theatre and Society (2000) и другие.

Проблема сценического перевода сводится к нескольким основным вопросам. В настоящей работе приведем лишь важнейшие понятия и положения. Следует учесть, что многие их них называют одно и то же явление. Таким примером является сценичность [англ. performability] текста. Этот термин имеет обобщающий характер. Мэри Снэлл-Хорнби, одна из важнейших теоретиков театрального перевода, считает, что текст перевода для сцены - это произведение, предназначенное для устной презентации, однако никогда не тождественное живой речи. В нем совместно действуют разного рода стилистические средства, влияющие на зрителя, а слова актера являются для него лишь театральной маской, отображающей черты его характера и поведение. Кроме того, сценическое действие должно влиять на зрителя и побуждать его к реакциям (Snell-Hornby 2007, 106-119). Это также суть театрального перевода.

Помимо прочего, существует еще часто встречаемое понятие удобопроизносимость (англ. speakability). Удобопроизносимость - это явление, в котором переводчик избегает употребления выражений и фраз, которые сложно произнести, и в случае которых зритель может ослышаться. Конечно, существует мнение, что это явление лишь «отговорка для ленивых думать, говорить и слушать» (Олицкая 2012, 20). Другие считают, что это опасно, так как может 
привести к банализации значений и доместикации перевода (Aaltonen 2000, 43). По мнению сторонников этого подхода, значимая роль принадлежит здесь актеру - важными являются его профессиональная подготовка и талант, позволяющие ему произнести любой текст ${ }^{2}$.

Иржи Левый выделяет еще понятие "удобопонятность», тесно связанное с вышеприведенным. Удобопонятность, как удобопроизносимость, ставит в центре внимания звуковую сторону высказывания. Дело в том, чтобы текст, звучащий со сцены, но также любые другие звуки, были хорошо понятны зрителю. В том числе рассматривается акустика зрительного зала, внятность отдельных согласных, звуки и музыка во время постановки. Внимание уделяется также «вероятности сочетания» некоторых фраз, т.е. зритель хуже воспринимает фразы и выражения, которых не знает, напр., названия реалий, историзмы, фразеологизмы и пр. Нам кажется, что это имеет особое значение, так как коммуникационная возможность рецепции зрителя должна учитываться в процессе любого перевода (Parchem 2014, 72).

Вызовом в случае театрального перевода являются также невербальные элементы текста, остальные элементы семиотической системы театра, языковая экономия, имплицитные элементы как средство реализации подтекста. Зритель во время просмотра постановки получает информацию одновременно по нескольким каналам восприятия - он видит, слышит, чувствует - что должно учитываться переводчиком. Очевидным является то, что сохранение всех этих элементов практически невозможно (Bassnett 1998, 91; 2002, 124-130).

Это далеко не все барьеры в переводе для сцены. Они, несомненно, предопределяют качественность перевода. Переводчику следует помнить о том, что текст в процессе перевода нельзя упрощать или сглаживать. К этому еще добавляются типично художественные элементы. А их переводчик не может осмыслять с помощью текста. В качестве примера можно привести реалии, которые в печатном тексте можно объяснить с помощью сноски или комментария. В переводе для театра нет места для такого решения. Тогда переводчики пользуются другими знаками театра, например, жестом или реквизитом. Тем самым переводчик становится элементом театрального коллектива, объясняя актерам и режиссерам некоторые свои переводческие решения и приемы. Переводчики, как правило, все чаще участвуют в застольных репетициях или театральных читках, во время которых могут высказаться на тему перевода. Имеют тогда возможность подсказать, что именно должно быть доминантой данной сцены. Не удивительно тогда, что многие исследователи считают, что лишь сцена и вербальная интеракция актеров дает переводчику возможность почувствовать театральный язык.

Наряду с вышеприведенным необходимо отметить мнение практиков театра. В качестве примера мы приведем слова польской переводчицы - Агнешки Любомиры Пиотровской относительно ее работы над текстом и с театральным коллективом. Переводчица во многих интервью подчеркивает, что для нее очень важно «услышать текст» таким, каким он есть в оригинале. Тогда только она может понять его ритм, рифму и пр. Потом, она представляет себе возможную реализацию и актеров, которые высказывают ее текст. Следовательно, звуковая сторона текста имеет для нее особое значение. Так было и в случае перевода Вишневого сада Антона Чехова. После прослушивания аудиокниги переводчица поняла, что все персонажи, кроме Лопахина, говорят с ошибками. Она старалась аналогично отобразить это в польском переводе. Пиотровска не старается осовременить своих переводов, хотя их актуализирует. Оставляет также элементы «категории чуждого». Что может приводить ко многим

\footnotetext{
${ }^{2}$ Считаем, что эти вопросы весьма существенны. Ср. М. Малек, Адресатные формы в сценическом переводе, 2019. В: Przestrzenie Przekładu 4, Katowice 2020, с. 175-188.
} 
семантическим и стилистическим потерям (относительно названий реалий или имен собственных). Они были обнаружены нами в наших исследованиях. Пиотровска подчеркивает, что в ее в ее работе существенной оказывается связь с актерами и режиссером. Она всегда старается присутствовать на первых репетициях. Это дает ей возможность высказаться на тему своих переводческих решений - оправдать некоторые выборы, а также обратить внимание актеров и других на элементы, которые нуждаются в дополнительном осмыслении (интонация, жесты, движения или реквизиты).Все это является неотъемлемой частью процесса перевода. Во время таких консультаций переводчик обрабатывает дополнительно свой текст, делая его театральным, сценичным, качественным.

Из этого вытекает, что в процессе перевода для театра появляются вызовы типичные для перевода художественных текстов, и дополнительно - новые, свойственные только ему.

Надо также иметь в виду то, что читателю не интересен факт с каким произведением он общается - оригинальным или переводным. И в том, и в другом случае он воспринимает его, как результат художественного творчества и стремится получить от него эстетическое наслаждение. В связи с этим переводчик, хотя его работа может быть не замечена, должен бороться за успех постановки, а также за то, чтобы зритель получил от нее максимум удовольствия.

\section{Использованная литература / References}

\section{Печатные источники:}

AALTONEN, S. (2000): Time-sharing on Stage: Drama Translation in Theatre and Society. Clevedon: Multilingual Matters, 2000. 121 c. ISBN 978-1853594700.

BASSNETT, S. (1998): Still Trapped in the Labyrinth: Further Reflections on Translation and Theatre. In Constructing Cultures. Clevedon: Multilingual Matters, 1998. 143 c. ISBN 978-18-5359-353-6.

BASSNETT, S. (2002): Translation Studies, 3rd edition. London and New York: Routledge, 2002. 175 c. ISBN 0-20342746-7.

CSATÓ, E. (2003): Funkcje mowy scenicznej. In Problemy teorii dramatu i teatru 2. Wrocław: Wydawnictwo Uniwersytetu Wrocławskiego, 2003. 528 c. ISBN 83-229-2448-8.

HEJWOWSKI, K. (2015): Iluzja Przekładu. Katowice: Wydawnictwo „Śląsk”, 2015. 440 c. ISBN 978-83-7164-890-8. LEWICKI, R. (2017): Zagadnienia lingwistyki przekładu. Lublin: Wydawnictwo Uniwersytetu Marii CurieSkłodowskiej, 2017. 362 c. ISBN 978-83-7784-956-9.

MILLAN, C. (2013): The Routledge Handbook of Translation Studies. London and New York: Routledge, 2013. 574 C. ISBN 978-0-415-55967-6.

NDIAYE, I. A. (2016): O specyfice kulturowo-językowej monodramu Jewgienija Griszkowca „Jak zjadłem psa” i potencjalnych oraz realnych reperkusjach przekładowych z uwzględnieniem tłumaczenia na język polski. In Acta Neophilologica XVIII (2). Olsztyn: Wydawnictwo Uniwersytetu Warmińsko-Mazurskiego, 2016. 256 c. ISSN 15091619.

PARCHEM, W. (2014): Kwestia sceniczności tłumaczeń utworów dramatycznych w wybranych badaniach nad przekładem. In Acta philologica 45. Warszawa: Wydawnictwo Uniwersytetu Warszawskiego, 2014. 235 c. ISSN 0065-1524.

SKWARCZYŃSKA, S. (1973): Swoisty problem przekładu tekstu dramatycznego. In Na križovatce umeni. Brno: Univ. J. E. Purkyně, 1973. 514 c.

SNELL-HORNBY, M. (2007): Theatre and Opera Translation. In A Companion to Translation Studies. Clevedon: Multilingual Matters, 2007. 186 c. ISBN 978-1-85359-956-9.

TOKARZ, B. (2010): Spotkania. Czasoprzestrzeń przekładu artystycznego. Katowice: Wydawnictwo Uniwersytetu Śląskiego, 2010. 277. ISBN 0208-6336.

TOMASZKIEWICZ, T. (2015): Przekład audiowizualny. Warszawa: PWN, 2015. 233 c. ISBN 978-83-0114-637-5. 
АлИМОВ, В. В. (2004): Теория перевода, Перевод в сфере профессиональной коммуникации. Москва: Едиториал УРСС, 2004. 162 с. ISBN 5-354-00660-0.

АХМАНОВА, О.С. (2007): Словарь лингвистических терминов. Москва: Едиториал УРСС, 2004. 571 с. ISBN 978-5-484-00932-9.

ГОРШКОВА, В. Е. (2006): Особенности перевода фильмов с субтитрами. In Сибирский журнал науки и технологии. Крсаноярск: Издательство Сибирского государственного аэрокосмического университета имени академика М. Ф. Решетнева, 2006. 185 с. ISSN 2587-6066.

ЛЕВЫЙ, И. (1974): Искусство перевода. Москва: Прогресс, 1974. 398 с.

ОлИЦкАЯ, Д. А. (2012): Перевод драмы: специфика, проблемы, подходы. In Вестник Томского государственного университета. Томск: Издательство Томского государственного университета, 2012. 221 c. ISSN 1561-7793.

\section{Онлайн-источники:}

SMITH, P. (онлайн): Supertitles. In Arts Review 3/1986. Washington, The Endowment, 1986, 36 с. Режим доступа: https://play.google.com/books/reader?id=Qm7mtBG6BNQC\&hl=pl\&pg=GBS.PP1 [дата обращения: 23.04.2020].

АНОСОВА, Н.Э. (онлайн): Закадровый перевод и субтитрирование: особенности и перспективы. In Перспективы Науки и Образования 1 (31), 2018. 268 с. ISSN 2307-2334.

https://cyberleninka.ru/article/n/zakadrovyy-perevod-i-subtitrirovanie-osobennosti-i-perspektivy [дата обращения: 25.05.2020].

ГАЙНАНОВА, Г. (онлайн): Переводчики театра Камала: Мы тоже участвуем в спектакле. Сайт События. Режим доступа: www.sntat.ru/news/culture/14-12-2017/perevodchiki-teatra-kamala-my-tozhe-uchastvuemv-spektakle-5636887 [дата обращения: 18.06.2019].

ГРИШКОВЕЦ, Е. (онлайн): Как Гришковец съел собаку - интервью с Е. Гришковцом. Сайт еженедельного журнала «Профиль». Режим доступа: www.rofile.ru/archive/kak-grishkovec-sel-sobaku-109455/ [дата обращения: 08.04.2020].

КАЛИНИНА, О. (онлайн): В Праге выступил российский режиссер и актер Евгений Гришковец. Сайт Radio Prague International. Режим доступа: www.radio.cz/ru/rubrika/novosti/v-prage-vystupil-rossijskij-rezhisser-iakter-evgenij-grishkovec [дата обращения: 10.04.2020].

ЭНЦИКЛОПЕДИЯ КРУГОСВЕТ (онлайн): драматургия. Режим доступа: https://www.krugosvet.ru/enc/kultura_i_obrazovanie/teatr_i_kino/DRAMATURGIYA.html [дата обращения: 05.04.2020].

\section{Профиль автора:}

Мачей Малек, аспирант, магистр

Научные интересы: теория перевода, художественный перевод, межъязыковая омонимия и паронимия e-mail: maciekmalek93@gmail.com

Место работы: Силезский университет, Институт языкознания, Сосновец, ул. Ген. С. Грота-Ровеского5, 41205, Польша

\section{Author'sprofile:}

Maciej Malek, doctoral student, MA

Research interests: Translation Theory, Artistic Translation, interlanguage homonyms and paronyms e-mail: maciekmalek93@gmail.com

Place of work: University of Silesia, Institute of Linguistics, Sosnowiec, gen. S. Grota-Roweckkiego 5 street, 41 205, Poland 